\title{
Nota Técnica
}

\section{Modelagem da qualidade da água do rio Poti em Teresina (PI)}

\author{
Water quality modeling at Poti river in Teresina (Piauí, Brazil)
}

Antônio Alves de Oliveira Filho', Iran Eduardo Lima Neto²

口-

\begin{abstract}
RESUMO
O crescimento desordenado da capital piauiense - marcado, sobretudo, pela ocupação habitacional às margens do rio Poti e pela existência de ligações clandestinas de esgoto bruto nas tubulações de drenagem pluvial - tem contribuído significativamente para a poluição das águas da bacia hidrográfica do rio Parnaíba (região semiárida do Brasil). A presente pesquisa tem como objetivo realizar a modelagem matemática da qualidade daágua em um trecho de 36,8 km de extensão do rio Poti, com base na plataforma QUAL-UFMG. A pesquisa apresenta-se como o primeiro estudo envolvendo modelagem da qualidade da água no referido rio. Os componentes modelados foram: oxigênio dissolvido (OD), demanda bioquímica de oxigênio (DBO) e coliformes termotolerantes (CT). Os resultados das medições de campo indicaram desconformidades do parâmetro CT com relação à Resolução CONAMA no 357/2005. A calibração dos coeficientes de decaimento para cada parâmetro resultou em desvios médios entre dados medidos e modelados de até $20 \%$ e coeficientes de eficiência de Nash-Sutcliffe superiores a 0,75, o que indica que - QUAL-UFMG pode ser utilizado como base para predição da qualidade da água em rios localizados em regiões semiáridas. O modelo calibrado também foi comparado aos dados de campo obtidos na literatura. Finalmente, foram realizadas simulações do modelo para diferentes cenários de vazão (mínimas e máximas), apresentando resultados coerentes e que podem ser utilizados para a gestão dos recursos hídricos do estado do Piauí.
\end{abstract}

Palavras-chave: modelagem matemática; qualidade da água em rios; semiárido.

\begin{abstract}
The uncontrolled growth of Piauís capital, in Brazil, characterized mainly by the occupation of the banks of the river Poti and the existence of illegal connections of raw sewage in rainwater drainage pipes, has contributed significantly to water pollution in the basin of Parnaiba river (semiarid region of Brazil). This research aims at performing the mathematical modeling of water quality in an area of $36.8 \mathrm{~km}$ of the Poti river, based on the QUAL-UFMG platform. The research is presented as the first study involving modeling of water quality in said river. Modeled components were: dissolved oxygen (DO), biochemical oxygen demand (BOD) and thermotolerant coliforms (TC). The results obtained from field measurements indicated nonconformities of the parameter TC with respect to CONAMA Resolution no 357/2005. The calibration of the decay coefficients for each parameter resulted in mean deviations between measured and modeled data of up to $20 \%$ and Nash-Sutcliffe efficiency coefficients higher than 0.75, which indicate that the QUAL-UFMG can be used as a basis for predicting the water quality in rivers of semiarid areas. The calibrated model was also compared to field data obtained from the literature. Finally, model simulations were performed for different flow scenarios (minimum and maximum), with consistent results that can be used for the management of the Piauí state water resources.
\end{abstract}

Keywords: mathematical modeling; river water quality; semiarid.

\section{INTRODUÇÃO}

Situada entre dois rios federais (Poti e Parnaíba), Teresina (PI) vem apresentando um crescimento urbano acentuado, porém desprovido de planejamento criterioso. Isso pode ser observado pelas ocupações habitacionais às margens dos rios e ligações clandestinas de esgoto bruto nas tubulações de drenagem pluvial. As implicações disso, somadas a uma gestão ambiental incipiente, vêm provocando diversos impactos socioeconômicos e ambientais na região, já que o baixo atendimento da população teresinense pelo sistema público de esgotamento sanitário resulta em graves consequências para a saúde humana, sobretudo nas áreas mais carentes de infraestrutura básica.

A bacia hidrográfica do rio Poti possui maior densidade demográfica na cidade de Teresina. Portanto, a avaliação da qualidade das suas águas no trecho que corta a capital piauiense é de suma importância para a gestão dos recursos hídricos da região. Câmara (2011) e Oliveira (2012) avaliaram a qualidade da água do rio Poti nos períodos $\square$

Mestrando em Recursos Hídricos pela Universidade Federal do Ceará (UFC) - Fortaleza (CE), Brasil. Engenheiro Civil do IFPI. ${ }^{2}$ Doutor em Engenharia Hidráulica pela University of Alberta. Professor da UFC - Fortaleza (CE), Brasil.

Endereço para correspondência: Iran Eduardo Lima Neto - Departamento de Engenharia Hidráulica e Ambiental da Universidade Federal do Ceará - Campus do Pici Bloco 713, 10 andar - 60451-970 - Fortaleza (CE), Brasil - E-mail: iran@deha.ufc.br

Recebido em: 01/11/16 - Aceito em: 28/11/16 - Reg. ABES: 142354 
de estiagem e cheia, no município de Teresina, analisando parâmetros físico-químicos e biológicos, visando sua classificação de acordo com a resolução CONAMA n 357/2005 (BRASIL, 2005), bem como sua adequação aos diversos usos. Ambos os estudos apontaram desconformidades com relação à resolução supracitada. Por outro lado, o Piauí ainda carece de estudos envolvendo modelagem matemática da qualidade da água dos seus corpos hídricos, que possam servir como base para a previsão de diferentes cenários ambientais para a região.

O QUAL2E é um modelo clássico largamente utilizado para simulação do impacto de cargas de efluentes em cursos de água, bem como para definição de cargas permissíveis e demais considerações associadas à qualidade das águas. Constitui uma versão atualizada do modelo QUALII, desenvolvido pela NCASI (National Council for Air and Stream Improvement), juntamente com o Center for Water Quality Modeling (CWQM) da EPA (United States Environmental Protection Agency) (Brown \& Barnwell, 1987; CHAPRA, 1997; CHAUDHURY et al., 1998; NING et al., 2001). Esse modelo é bastante versátil e possibilita a avaliação de processos que envolvem vários constituintes ao decorrer de um curso de água: oxigênio dissolvido, demanda bioquímica de oxigênio, concentração de biomassa algal, nitrogênio orgânico, amônia, nitrito, nitrato, fósforo orgânico, fósforo dissolvido e coliformes. O modelo QUAL2K surgiu como sucessor do QUAL2E. As principais diferenças entre os modelos supracitados são apresentadas por Chapra et al. (2008).

Em âmbito nacional, diversos estudos envolvendo modelagem da qualidade da água em rios têm sido realizados usando o QUAL2E e, mais recentemente, o QUAL2K (GASTALDINI et al., 2002; PALMIERI \& CARVALHO, 2006; SILVA, 2007; SABIÁ, 2008; Mourão JÚnior, 2010; SABÓIA, 2011; PORTO et al., 2011). Alternativamente, Von Sperling (2007) desenvolveu a plataforma QUAL-UFMG a partir de simplificações do modelo QUAL2E e adaptação de suas equações para planilhas eletrônicas em Excel. As principais simplificações do modelo QUALUFMG em relação ao QUAL2E consistem na desconsideração da dinâmica de algas e da dispersão longitudinal. A literatura dispõe de diversos trabalhos científicos sobre o uso do QUAL-UFMG, tais como: Mourão Júnior (2010), Salla et al. (2013) e Teodoro et al. (2013). Cabe salientar que nos referidos estudos, o QUAL-UFMG foi aplicado a cursos de água perenes, localizados nas regiões Centro-Oeste e Sudeste do Brasil.

Desse modo, esta pesquisa tem como objetivo calibrar e testar a plataforma QUAL-UFMG para modelagem da qualidade da água no rio Poti, na cidade de Teresina, bem como simular diferentes cenários de vazão (máximas e mínimas) inerentes ao semiárido. Além de configurar-se como o primeiro estudo de modelagem da qualidade da água no referido rio, não foram encontrados trabalhos na literatura que utilizassem o QUAL-UFMG para modelagem da qualidade da água em rios localizados em regiões semiáridas, ou ainda em trechos de rios urbanos sujeitos a múltiplas descargas de esgoto ao longo de seu trajeto, como é o caso do rio Poti em Teresina.

\section{METODOLOGIA}

\section{Área de Estudo}

Pertencente à bacia hidrográfica do rio Parnaíba (região semiárida do Brasil), a bacia do rio Poti nasce sobre rochas cristalinas, pré-cambrianas, no Ceará, nas proximidades da cidade de Algodões, pela junção dos riachos Santa Maria e Algodões. A bacia do rio Poti abrange uma área de $52.370 \mathrm{~km}^{2}$, sendo que $38.797 \mathrm{~km}^{2}$ encontram-se no Piauí e, o restante, no Ceará. Está localizada entre as coordenadas geodésicas $04^{\circ} 06^{\prime}$ e $06^{\circ} 56^{\prime}$ de latitude sul, e entre $40^{\circ} 00^{\prime}$ e $42^{\circ} 50^{\prime}$ de longitude oeste (SEMAR, 2004).

O trecho estudado do rio Poti possui extensão de $36,8 \mathrm{~km}$ e corta a cidade de Teresina, conforme mostrado esquematicamente na Figura 1.

\section{Coleta e Análise de Dados}

O mês de abril de 2014 foi utilizado como base para os estudos de campo. Para a obtenção das vazões no rio Poti nesse período, foram utilizados inicialmente os dados históricos de vazão e altura da água entre 2002 e 2007 (Figura 2), referentes à Estação Fluviométrica Fazenda Cantinho II (Código no 34789000) da Agência Nacional de Águas (ANA), por estar localizada no início do trecho selecionado para esta pesquisa (ver ponto PR0 na Figura 1 e Figura 3). Em seguida, foi obtida uma curva-chave do tipo potência, relacionando a vazão do rio à altura da água (ver Figura 4A). Posteriormente, de posse de dados de altura da água referentes ao período do estudo (abril de 2014) fornecidos pelo Serviço Geológico do Brasil (CPRM), foi possível determinar a vazão média do rio para o ponto inicial da modelagem (PR0), por meio da curva-chave supracitada.

Conforme indicado na Figura 1, foram coletadas amostras para realização de análises físico-químicas e bacteriológicas em 13 pontos de esgotos (galerias pluviais) que deságuam no rio Poti, e mais 4 pontos ao longo do curso d'água, objetivando obter dados de entrada na plataforma QUAL-UFMG e calibrar o modelo por meio de ajuste dos coeficientes de decaimento para os parâmetros: oxigênio dissolvido (OD), demanda bioquímica de oxigênio (DBO) e coliformes termotolerantes (CT). Os resultados das análises do rio foram cedidos pelo Centro de Tecnologia da Universidade Federal do Piauí (UFPI), onde se avalia mensalmente a qualidade da água do rio Poti por meio do Índice de Qualidade da Água (IQA). As análises nos 13 pontos de esgotos, em relação aos mesmos parâmetros analisados no rio, foram realizadas pela concessionária Águas e Esgotos do Piauí S. A. (AGESPISA), exclusivamente para esta pesquisa.

Os pontos monitorados nas galerias pluviais instaladas ao longo do rio Poti, com a denominação de pontos de esgoto, bem como os pontos monitorados no referido rio para obtenção de dados de entrada no QUAL-UFMG e calibração do modelo, são descritos detalhadamente nas Tabelas 1 e 2. O Ponto PE11 (Tabela 1) corresponde ao despejo de 
efluente tratado da estação de tratamento de esgoto (ETE-LESTE) da cidade de Teresina. As informações de vazão do referido ponto foram fornecidas pela AGESPISA.

Para a determinação das vazões das galerias pluviais, foi utilizado o princípio da energia específica, considerando regime crítico no ponto de queda brusca da água (PORTO, 2006). Para isso, considera-se que, na saída das galerias, o escoamento passa de regime fluvial para torrencial (curva do tipo $\mathrm{M}_{2}$, conforme descrito por Porto, 2006), atingido, portanto, a sua altura crítica - isto é, aquela que fornece número de Froude igual a 1,0, possibilitando assim o cálculo das vazões específicas para cada caso. Posteriormente, foram calculadas as vazões de esgoto pelo produto da vazão específica e a largura das galerias pluviais.
Nas galerias circulares, foram feitas equivalências de áreas para escoamentos retangulares. O monitoramento das alturas críticas (in loco) foi realizado diariamente entre $8 \mathrm{~h}$ e $16 \mathrm{~h}$, com intervalos entre medições variando entre duas e quatro horas, durante o mês de abril de 2014.

A Figura 3 mostra o diagrama unifilar da área de estudo, identificando as distâncias entre os 13 pontos de esgotos (galerias pluviais) monitorados ao longo do rio Poti, até a confluência com o Rio Parnaíba.

\section{Equações do Modelo}

O QUAL-UFMG assume mistura completa em cada ponto de lançamento de esgoto. Assim, a Equação 1 é utilizada para cálculo da média ponderada das concentrações com as vazões dos elementos que se

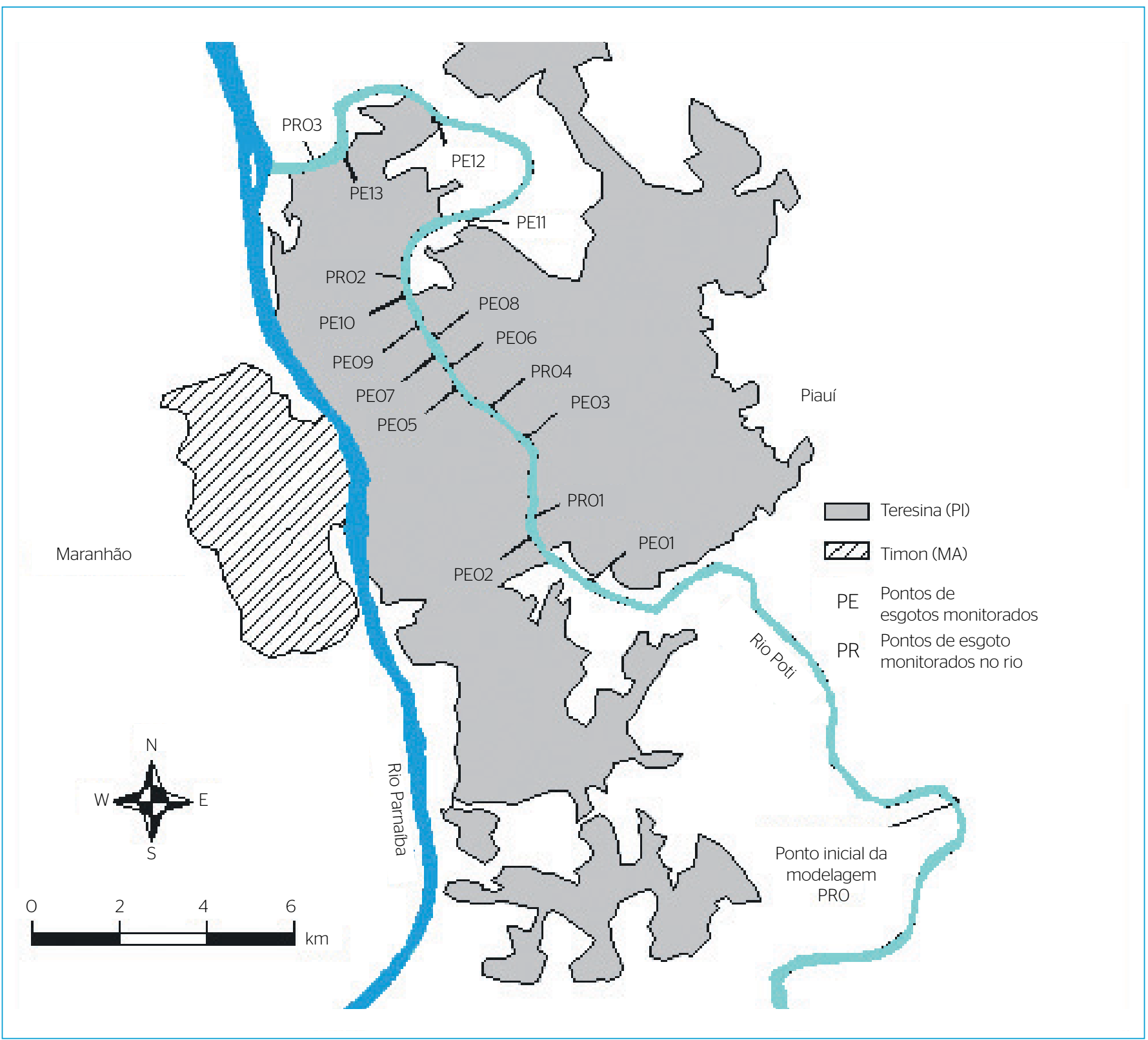

Figura 1 - Trecho estudado do rio Poti (Teresina, PI), com destaque para os pontos monitorados. 


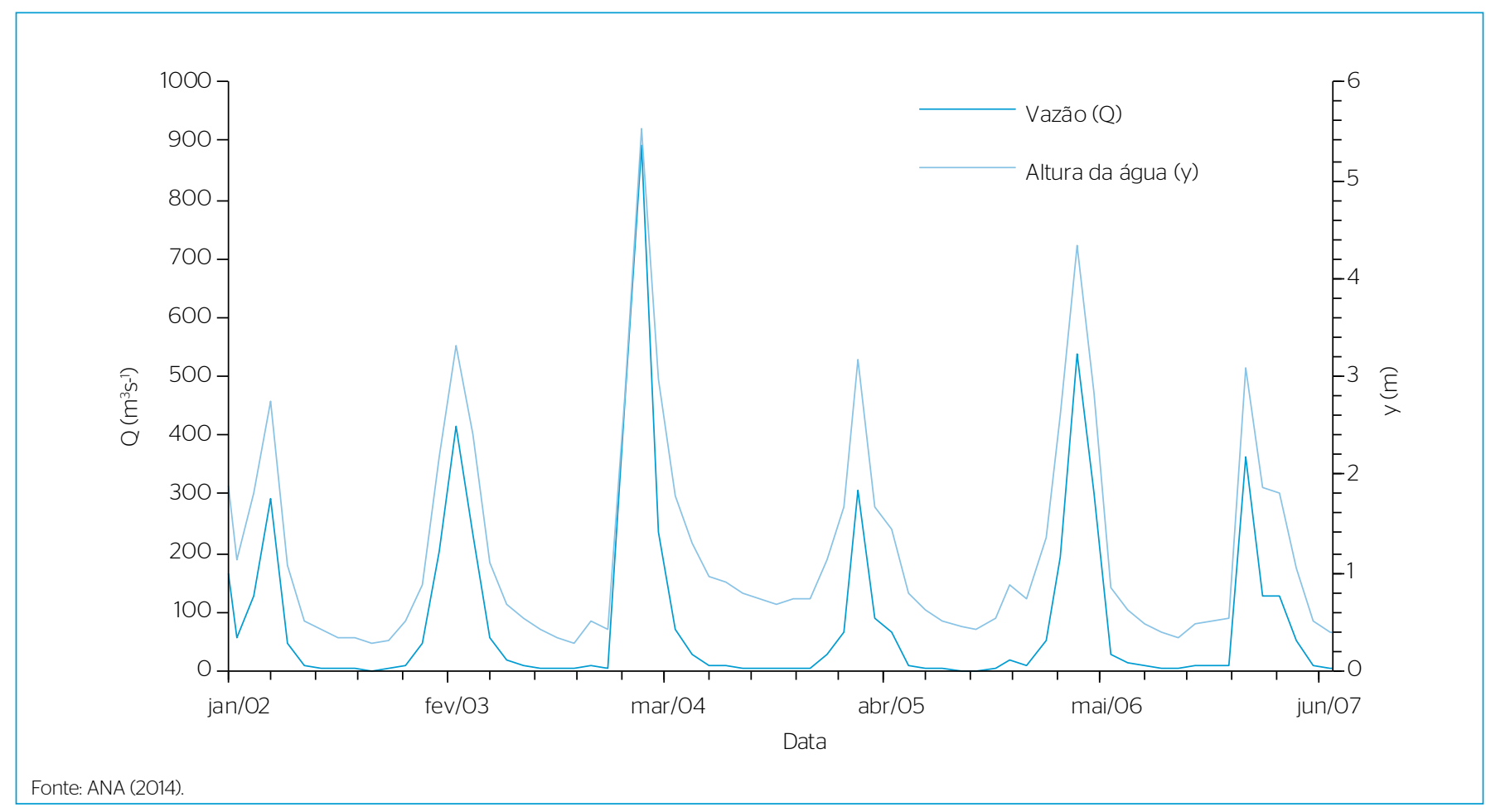

Figura 2 - Vazões e alturas da água observadas no rio Poti em Teresina (PI) entre 2002 e 2007.

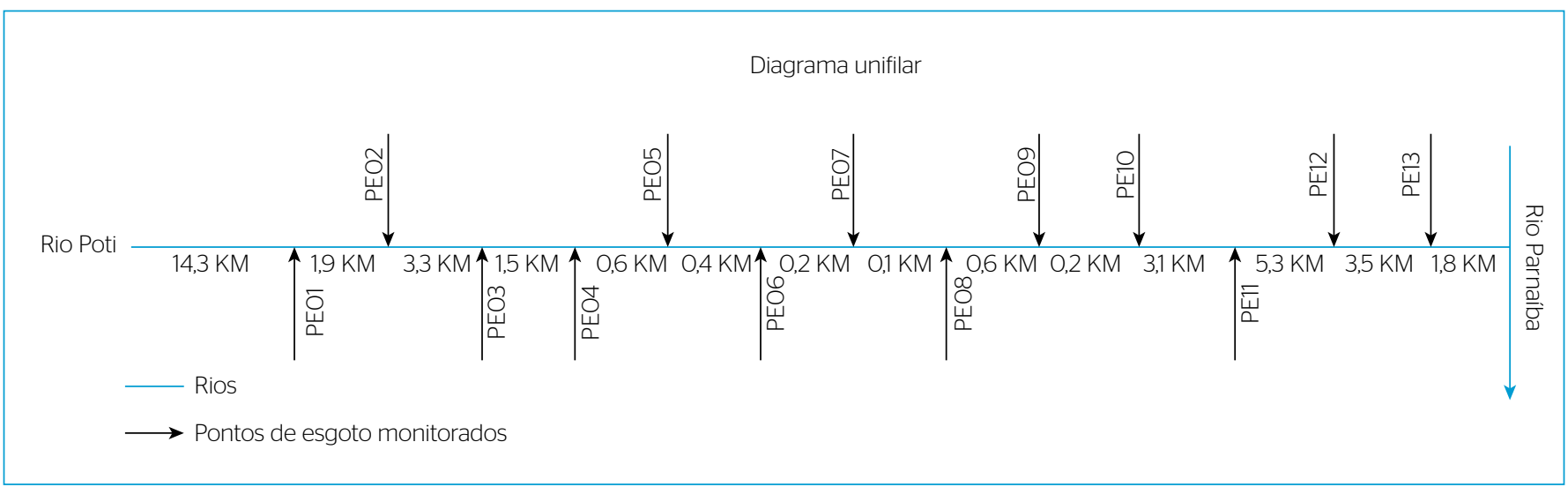

Figura 3 - Diagrama unifilar da área de estudo.

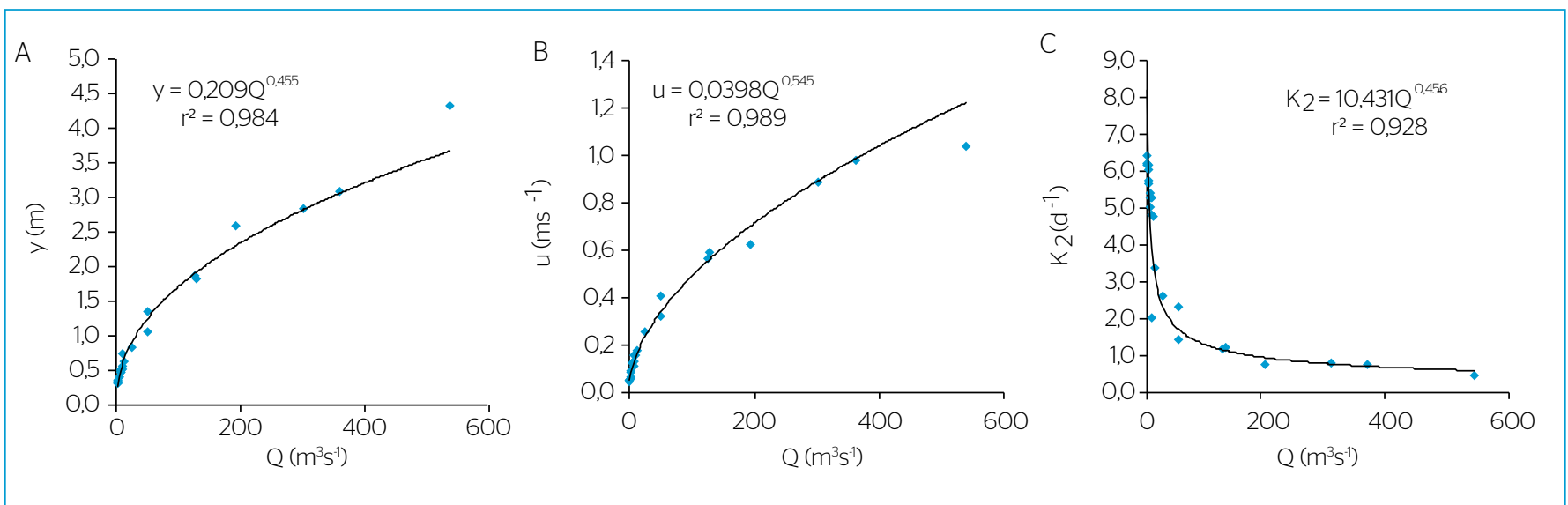

Figura 4 - Ajuste de relações empíricas do modelo: (a) altura x vazão, (b) velocidade x vazão, e (c) coeficiente de reaeração x vazão. 
agregam, podendo se tratar de OD, DBO, nitrogênio, fósforo e coliformes termotolerantes (Von Sperling, 2007):

$\frac{Q_{R} \cdot C_{R}+Q_{E} \cdot C_{E}}{Q_{R}+Q_{E}}$

onde:

$\mathrm{C} 0=$ concentração na mistura $\left(\mathrm{mg} \mathrm{L}^{-1}\right)$;

$\mathrm{CR}=$ concentração no rio a montante do ponto de mistura $\left(\mathrm{mg} \mathrm{L}^{-1}\right)$;

$\mathrm{CE}=$ concentração do esgoto a montante do ponto de mistura $\left(\mathrm{mg} \mathrm{L}^{-1}\right)$;

$\mathrm{QR}=$ vazão do rio $\left(\mathrm{m}^{3} \mathrm{~s}^{-1}\right)$;

$\mathrm{QE}=$ vazão do esgoto $\left(\mathrm{m}^{3} \mathrm{~s}^{-1}\right)$.

Para a modelagem de coliformes termotolerantes, o decaimento bacteriano é estimado pela equação unidimensional de transporte de massa (desprezando os termos transiente e de difusão/dispersão), em que o termo de advecção pode ser considerado diretamente proporcional a um termo de reação de $1^{\mathrm{a}}$ ordem que representa o decaimento de bactérias, como mostra a Equação 2:

$u \frac{d N}{d x}=-K_{b} \cdot N$

onde:

$\mathrm{N}=$ quantidade de coliformes termotolerantes por volume (NMP/100 ml);

$\mathrm{u}=$ velocidade média da água no trecho em estudo;

$\mathrm{x}=$ coordenada ao longo da trajetória do rio;

$\mathrm{Kb}=$ coeficiente de decaimento bacteriano $\left(\mathrm{d}^{-1}\right)$.
Expressando a equação anterior por meio do método de diferenças finitas e usando o método de Euler, obtém-se a seguinte expressão algébrica (Equação 3):

$N_{i+1}=N_{i}-K_{b} \cdot N_{i} \cdot\left(\frac{\Delta x}{u}\right)$

De forma semelhante, a equação para a DBO pode ser expressa como (Equação 4):

$u \frac{d L}{d x}=-K_{d} \cdot L$

onde:

$\mathrm{L}=$ concentração de DBO $\left(\mathrm{mg} \mathrm{L}^{-1}\right)$;

$\mathrm{Kd}=$ coeficiente global de decaimento de DBO $\left(\mathrm{d}^{-1}\right)$.

Cabe salientar que, na presente pesquisa, considerou-se que os efeitos de remoção e sedimentação de DBO, assim como a demanda

Tabela 2 - Pontos monitorados no rio Poti em Teresina.

\begin{tabular}{|c|c|c|}
\hline Ponto & Latitude & Longitude \\
\hline PR O & $05^{\circ} 10^{\prime} 12.55^{\prime \prime}$ & $42^{\circ} 40^{\prime} 59.44^{\prime \prime}$ \\
\hline PR O1 & $05^{\circ} 06^{\prime} 53.28 "$ & $42^{\circ} 46^{\prime} 41.97^{\prime \prime}$ \\
\hline PR O2 & O5 O3' 49.41" & $42^{\circ} 48^{\prime} 25.36^{\prime \prime}$ \\
\hline PR O3 & $05^{\circ} 02^{\prime} 0.94^{\prime \prime}$ & $42^{\circ} 49^{\prime} 44.02^{\prime \prime}$ \\
\hline
\end{tabular}

Tabela 1 - Pontos de esgoto (galerias pluviais) monitorados ao longo do rio Poti em Teresina.

\begin{tabular}{|c|c|c|c|c|}
\hline Ponto & Latitude & Longitude & Tipo & Características físicas \\
\hline PE 01 & $05^{\circ} 07^{\prime} 29.60^{\prime \prime}$ & $42^{\circ} 45^{\prime} 51.79^{\prime \prime}$ & Galeria Quadrada Triplo de Concreto & $\begin{array}{l}\text { Largura: 2,00m } \\
\text { Altura: 2,00m }\end{array}$ \\
\hline $\mathrm{PE} \mathrm{O2}$ & $05^{\circ} 06^{\prime} 57.38^{\prime \prime}$ & $42^{\circ} 46^{\prime} 41.66^{\prime \prime}$ & Galeria Circular Simples de Concreto & Diâmetro: 1,50m \\
\hline PE O3 & $05^{\circ} 05^{\prime} 14.96 "$ & $42^{\circ} 47^{\prime} 05.83^{\prime \prime}$ & Galeria Quadrada Simples de Concreto & $\begin{array}{c}\text { Largura: 4,0m } \\
\text { Altura: 2,5m }\end{array}$ \\
\hline PE O4 & $05^{\circ} 04^{\prime} 53.50^{\prime \prime}$ & $42^{\circ} 47^{\prime} 39.78^{\prime \prime}$ & Galeria Circular Quádruplo de Concreto & Diâmetro unitário: 1,5 \\
\hline PE O5 & O5 $04^{\prime} 39.10^{\prime \prime}$ & $42^{\circ} 47^{\prime} 56.20^{\prime \prime}$ & Galeria Circular Duplo de Concreto & Diâmetro unitário: 1,0m \\
\hline PE 06 & $05^{\circ} 04^{\prime} 26.98^{\prime \prime}$ & $42^{\circ} 47^{\prime} 57.78^{\prime \prime}$ & Galeria Circular Duplo de Concreto & Diâmetro unitário: 1,5m \\
\hline PE O7 & $05^{\circ} 04^{\prime} 22.50^{\prime \prime}$ & $42^{\circ} 48^{\prime} 07.40^{\prime \prime}$ & Galeria Quadrada Simples de Concreto & $\begin{array}{l}\text { Largura: 2,0m } \\
\text { Altura: 1,5m }\end{array}$ \\
\hline PE O8 & $05^{\circ} 04^{\prime} 18.00^{\prime \prime}$ & $42^{\circ} 48^{\prime} 04.98^{\prime \prime}$ & Galeria Circular Simples de Concreto & Diâmetro: 1,50m \\
\hline PE O9 & $05^{\circ} 04^{\prime} 04.80^{\prime \prime}$ & $42^{\circ} 48^{\prime} 19.20^{\prime \prime}$ & Galeria Quadrada Simples de Concreto & $\begin{array}{l}\text { Largura: 2,5m } \\
\text { Altura: 1,5m }\end{array}$ \\
\hline PE 10 & $05^{\circ} 03^{\prime} 58.30 "$ & $42^{\circ} 48^{\prime} 23.40^{\prime \prime}$ & Galeria Circular Triplo de Concreto & Diâmetro unitário: 1,0m \\
\hline PE 11 & $05^{\circ} 02^{\prime} 42.47^{\prime \prime}$ & $42^{\circ} 47^{\prime} 51.17 "$ & \multicolumn{2}{|c|}{ EFLUENTE TRATADO DA ETE-LESTE DE TERESINA } \\
\hline PE 12 & $05^{\circ} 01^{\prime} 16.24^{\prime \prime}$ & $42^{\circ} 48^{\prime} 14.07^{\prime \prime}$ & Galeria Quadrada Simples de Concreto & $\begin{array}{l}\text { Largura: 2,5m } \\
\text { Altura: 2,0m }\end{array}$ \\
\hline PE 13 & $05^{\circ} 01^{\prime} 52.50^{\prime \prime}$ & $42^{\circ} 49^{\prime} 22.95^{\prime \prime}$ & Galeria Quadrada Simples de Concreto & $\begin{array}{l}\text { Largura: 1,2m } \\
\text { Altura: 1,3m }\end{array}$ \\
\hline
\end{tabular}


de oxigênio do sedimento, poderiam ser englobados em um único processo de decaimento representado pelo lado direito da Equação 4. Assim, pode-se obter a seguinte forma numérica para esta equação (Equação 5):

$L_{i+1}=L_{i}-K_{d} \cdot L_{i} \cdot \frac{\Delta x}{u}$

Finalmente, a cinética de OD pode ser descrita pela Equação 6:

$u \frac{d C}{d x}=K_{2}\left(C_{s}-C\right)-K_{d} \cdot L$

onde:

$\mathrm{C}=$ concentração de $\mathrm{OD}\left(\mathrm{mg} \mathrm{L}^{-1}\right)$;

Cs $=$ concentração de saturação $\left(\mathrm{mg} \mathrm{L}^{-1}\right)$;

$\mathrm{K} 2$ = coeficiente de reaeração $\left(\mathrm{d}^{-1}\right)$.

Ressalta-se que, devido à ausência de dados, os termos referentes à fotossíntese, respiração algal e nitrificação foram desconsiderados neste estudo. Logo, o balanço de OD pode ser descrito pela Equação 7:

$C_{i+1}=C_{i}+\left[K_{2, i}\left(C_{s, i}-C_{i}\right)-K_{d} \cdot L_{i}\right] \cdot \frac{\Delta x}{u}$

É importante destacar que, no presente estudo, diferentes passos $(\mathrm{Dx} / \mathrm{u})$ foram testados até que se atingisse a precisão adequada para o uso do método numérico supracitado.

\section{Relações Empíricas do Modelo}

As características hidráulicas do rio e o coeficiente de reaeração $\mathrm{K}_{2}$ a serem usados em cada trecho da modelagem foram obtidos com base em equações ajustadas a partir dos dados de campo (Equações 8 a 10):

$u=a \cdot Q^{b}$

$y=c \cdot Q^{d}$

$K_{2}=m \cdot Q^{n}$

onde:

$\mathrm{y}=$ profundidade da água $(\mathrm{m})$;

"a", "b”, “c”, "d", “m” e "n” constantes empíricas a serem ajustadas (ver Figura 4).

\section{Calibração/Simulação do Modelo}

Os coeficientes calibrados para a modelagem da qualidade da água do rio Poti foram o de decaimento bacteriano $\left(\mathrm{K}_{\mathrm{b}}\right)$ e o de remoção de DBO (Kd). Já os valores para o coeficiente de reaeração (K2) foram obtidos por meio das equações preditivas fornecidas por Von Sperling (2007) e ajustados em função da vazão (ver Figura 4C). Utilizou-se a ferramenta "solver" do Excel, de forma a minimizar-se os desvios médios entre os valores medidos de OD, DBO e CT e os valores simulados desses parâmetros utilizando o QUAL-UFMG, obedecendo às faixas de valores (restrições) de $\mathrm{K}_{\mathrm{b}}$ e Kd fornecidas por Von Sperling (2007) (ver Tabela 3). Vale destacar que, além do desvio médio, também foi calculado o coeficiente de eficiência de Nash-Sutcliffe (Nash \& Sutcliffe, 1970) como forma de aumentar a confiança nos resultados.

Após a calibração do modelo, foram realizadas simulações para comparação e validação dos resultados com dados de campo obtidos na literatura. Além disso, foram simulados diferentes cenários de vazão no rio Poti inerentes às variabilidades do semiárido: $\mathrm{Q}_{10}$ (vazão superada em $10 \%$ do tempo) e $Q_{90}$ (vazão superada em 90\% do tempo), ambas determinadas pelas vazões históricas da Estação Fluviométrica Fazenda Cantinho II da Agência Nacional de Águas (ANA), no período compreendido entre 2002 e 2007.

\section{RESULTADOS E DISCUSSÃO}

\section{Ajuste das Relações Empíricas e dos Coeficientes do Modelo}

A Figura 4 apresenta o ajuste das relações empíricas do modelo (Equações 8 a 10) no ponto inicial (PR0) do trecho estudado do rio Poti, as quais relacionam altura, velocidade e coeficiente de reaeração com a vazão do rio. Foram obtidos excelentes ajustes para essas relações, com coeficientes de determinação $r^{2}$ superiores a 0,90 para todos os parâmetros.

As Figuras 5, 6 e 7 apresentam, respectivamente, os resultados da calibração do modelo com relação aos parâmetros OD, DBO e CT ao longo do rio Poti para o período de abril de 2014. A vazão adotada nos cálculos foi de $39 \mathrm{~m}^{3} \mathrm{~s}^{-1}$. Essa vazão foi obtida por meio da curva-chave indicada na Figura $4 \mathrm{~A}$ e a partir da profundidade média da água de 1,1m fornecida pela CPRM no ponto PR0. A Tabela 3 mostra uma síntese dos coeficientes calibrados em comparação com as faixas de valores disponíveis na literatura. Os valores obtidos para os coeficientes de decaimento bacteriano $\left(\mathrm{K}_{\mathrm{b}}=0,50 \mathrm{~d}^{-1}\right)$ e de remoção de DBO $\left(K_{d}=0,68 d^{-1}\right)$ situaram-se dentro das faixas sugeridas por Von Sperling (2007). No entanto, os valores foram superiores aos reportados por Sabiá (2008) para o rio Salgado no semiárido cearense, que obteve $\mathrm{K}_{\mathrm{b}}=0,30 \mathrm{~d}^{-1}$ e $\mathrm{K}_{\mathrm{d}}=0,13 \mathrm{~d}^{-1}$. Esses resultados são consistentes com as temperaturas mais elevadas de Teresina, em comparação com as temperaturas observadas na região do Crato $(\mathrm{CE})$, onde foram realizados os estudos de Sabiá (2008). Entretanto, os valores calculados por Sabiá (2008) para o coeficiente de reaeração $\left(K_{2}\right)$ foram da mesma ordem de grandeza que os obtidos na presente pesquisa, uma vez que os rios Poti e Salgado apresentaram características hidráulicas semelhantes 


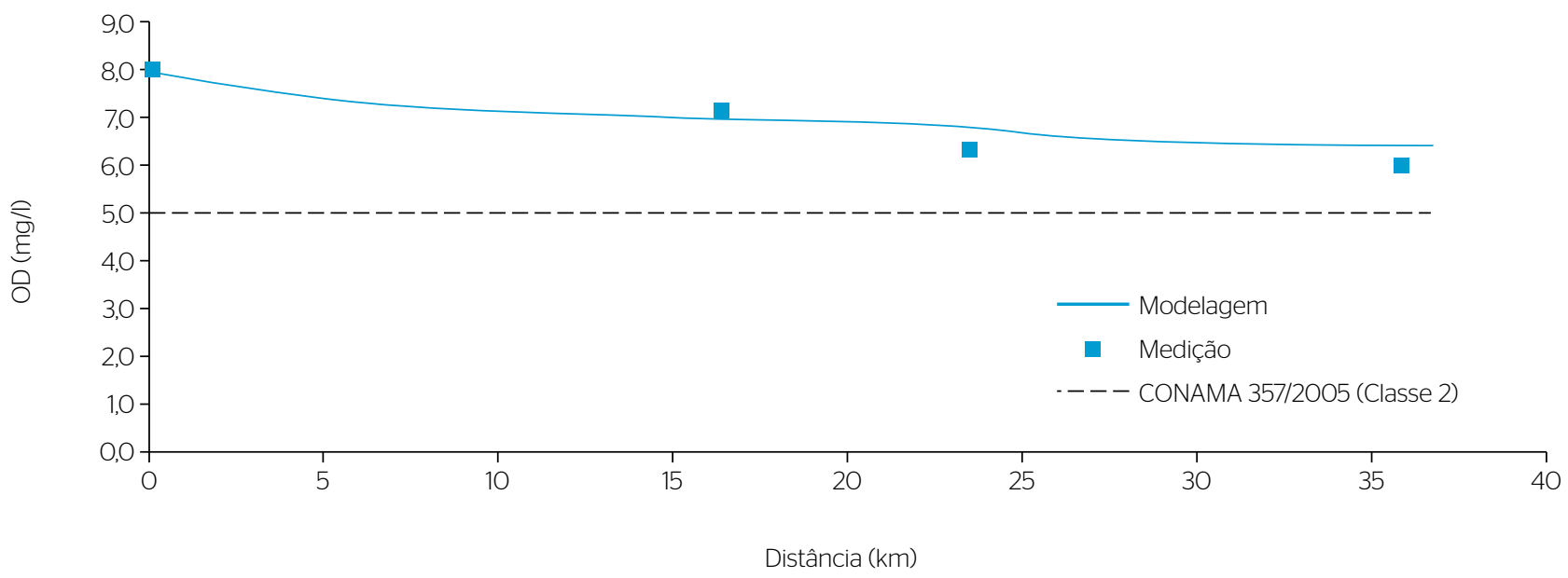

Figura 5 - Calibração da curva de oxigênio dissolvido (OD) e comparação com o limite estabelecido na Resolução CONAMA n $357 / 2005$ para a Classe 2.

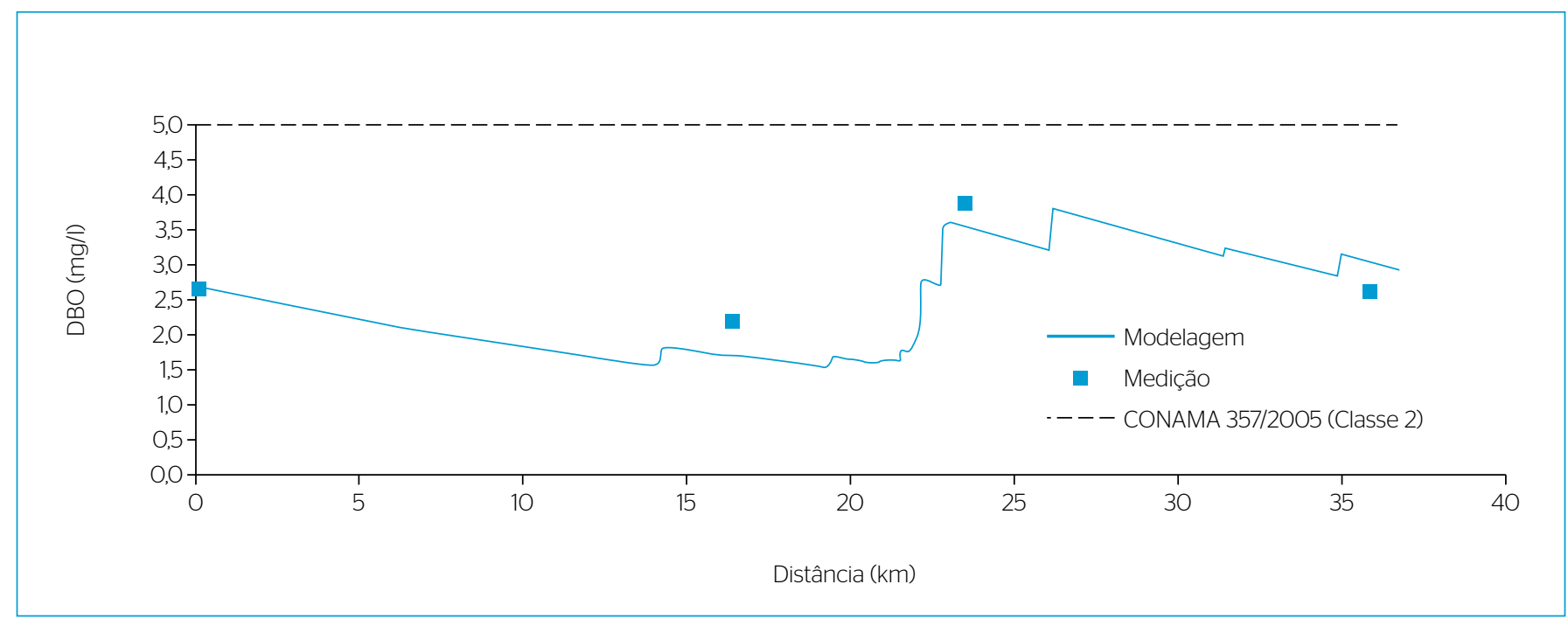

Figura 6 - Calibração da curva de demanda bioquímica de oxigênio (DBO) e comparação com o limite estabelecido na Resolução CONAMA no 357/2005 para a Classe 2.

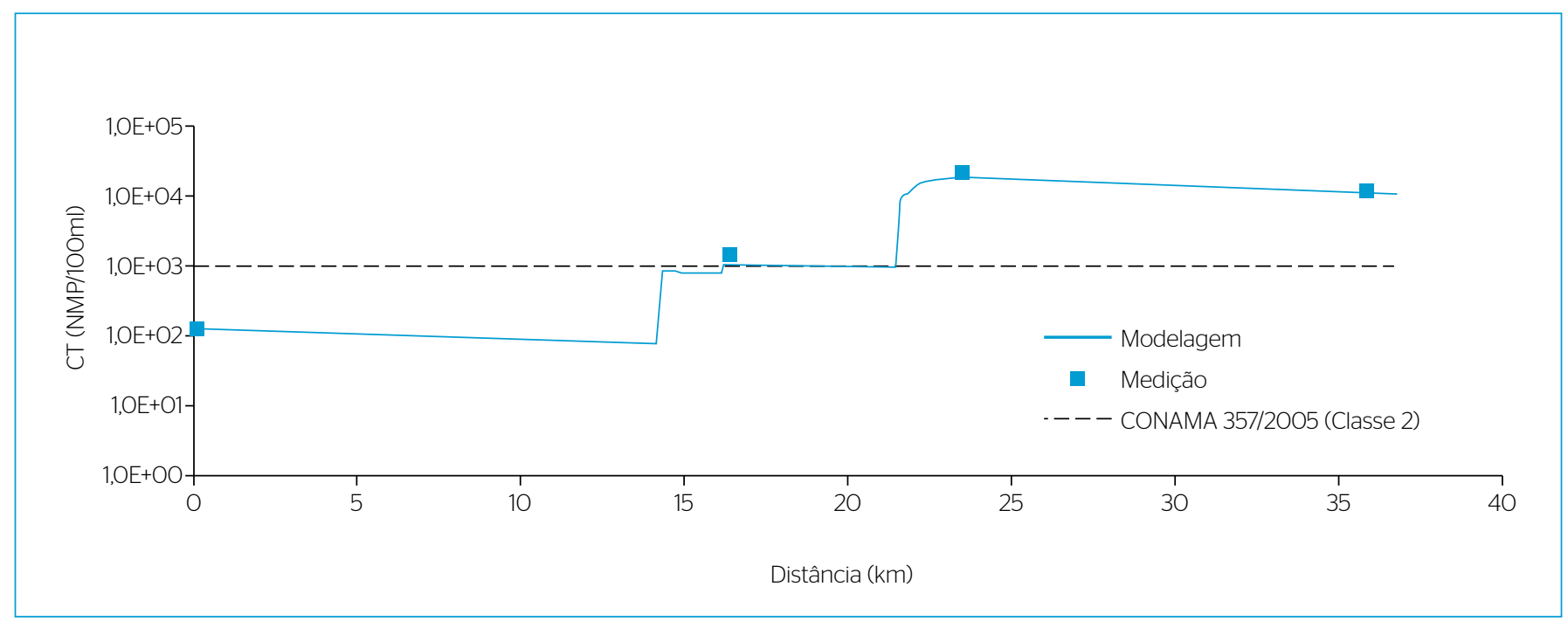

Figura 7 - Calibração da curva de coliformes termotolerantes (CT) e comparação com o limite estabelecido na Resolução CONAMA no $357 / 2005$ para a Classe 2. 
e, em ambos os casos, as equações preditivas de $\mathrm{K}_{2}$ foram as mesmas sugeridas por Von Sperling (2007).

\section{Oxigênio Dissolvido (OD)}

Conforme pode ser observado na Figura 5, o modelo calibrado forneceu uma excelente aderência aos dados de oxigênio dissolvido, obtidos em campo, com desvio médio de 7\% e coeficiente de eficiência de Nash-Sutcliffe de 0,905 . Isso indica que os processos referentes à fotossíntese, respiração algal e nitrificação representam termos de segunda ordem e que podem ser desconsiderados (em uma primeira aproximação) na modelagem do balanço de OD. A tendência clara de decaimento progressivo do OD justifica-se pela contribuição de matéria orgânica ao longo do trecho estudado, originária dos lançamentos clandestinos de esgoto doméstico interligados à drenagem pluvial da cidade de Teresina. Percebe-se, porém, que as concentrações de OD em toda extensão do rio $(36,8 \mathrm{~km})$ estão em conformidade com as determinações mínimas da Resolução CONAMA n 357/2005 para a Classe 2 (OD superior a $5 \mathrm{mg} \mathrm{L}^{-1}$ ).

\section{Demanda Bioquímica de Oxigênio (DBO)}

A Figura 6 mostra a calibração da curva de demanda bioquímica de oxigênio. Os resultados foram considerados satisfatórios, uma vez que o desvio médio entre os valores estimados e medidos foi de $19 \%$ e o coeficiente de eficiência de Nash-Sutcliffe foi de 0,779. Observa-se que o trecho estudado encontra-se novamente em conformidade com os limites estabelecidos na Resolução CONAMA no 357/2005 para a Classe 2 (DBO inferior a $5 \mathrm{mg} \mathrm{L}^{-1}$ ). A calibração gerou um coeficiente global de remoção da DBO (Kd) de 0,68 d-1 (ver Tabela 3). Isso sugere que a incorporação dos efeitos de remoção/sedimentação de DBO e da demanda de oxigênio do sedimento em um único processo de decaimento pode ser considerada na modelagem da qualidade da água do rio Poti.

\section{Coliformes Termotolerantes (CT)}

A Figura 7 apresenta a calibração do modelo com relação à variável coliformes termotolerantes. O coeficiente de decaimento bacteriano calibrado $(\mathrm{Kb})$ foi de $0,50 \mathrm{~d}^{-1}$ (ver Tabela 3 ). Os resultados podem ser considerados novamente satisfatórios, já que o desvio médio foi de $18 \%$ e o coeficiente de eficiência de Nash-Sutcliffe foi de 0,966. Ainda em observância à figura, pode-se afirmar que o rio Poti apresenta, na maior parte de sua extensão (55,7\% do trecho estudado), concentrações de coliformes termotolerantes fora dos limites estabelecidos na Resolução CONAMA n ${ }^{\circ} 357 / 2005$ para a Classe 2 (CT inferior a 1000 NMP/100 ml).

\section{Validação do Modelo}

As Figuras 8, 9 e 10 mostram simulações do modelo calibrado em comparação com os dados obtidos por Oliveira (2012), para uma vazão de $\mathrm{Q}=20 \mathrm{~m}^{3} \mathrm{~s}^{-1}$, e com os limites estabelecidos na Resolução CONAMA n ${ }^{\circ}$ 357/2005 (BRASIL, 2005) (Classe 2). Ressalta-se que essa vazão é aproximadamente a metade da vazão adotada na calibração, $Q=39 \mathrm{~m}^{3} \mathrm{~s}^{-1}, \mathrm{o}$ que resulta, de acordo com os valores simulados, em maiores faixas do rio em desconformidade com relação à legislação vigente. Percebe-se também que o modelo reproduz relativamente bem os dados de campo, mesmo considerando, como estimativa para a simulação, as mesmas cargas obtidas no presente estudo. As diferenças percentuais médias entre medida e modelagem com relação aos parâmetros OD, DBO e CT foram de 8,24 e $64 \%$, respectivamente, enquanto os coeficientes de eficiência de Nash-Sutcliffe foram de 0,439, 0,908 e 0,125, respectivamente. Resultados semelhantes também foram obtidos para outras vazões do rio Poti, medidas por Oliveira (2012). Logo, pode-se afirmar que as cargas obtidas nesta pesquisa, assim como os coeficientes calibrados, podem ser utilizados como referência para avaliar o comportamento dos parâmetros, principalmente OD e DBO, no rio Poti em Teresina. Embora os valores simulados para o parâmetro CT apresentem maiores discrepâncias em comparação com os demais parâmetros (OD e DBO), nota-se que o modelo representou razoavelmente (coeficiente de Nash-Sutcliffe superior a zero) a tendência geral de aumento progressivo das concentrações de CT ao longo do rio.

\section{Simulação de Cenários}

A Figura 11 mostra simulações de cenários utilizando o modelo calibrado e validado, considerando diferentes vazões no rio Poti inerentes às variabilidades do semiárido: $\mathrm{Q}_{10}$ (vazão superada em $10 \%$ do tempo) e $Q_{90}$ (vazão superada em 90\% do tempo). Em comparação com a vazão de referência $\mathrm{Q}=39 \mathrm{~m}^{3} \mathrm{~s}^{-1}$, utilizada na calibração do modelo, pode-se perceber que, para elevadas vazões $\left(\mathrm{Q}_{10}=304 \mathrm{~m}^{3} \mathrm{~s}^{-1}\right)$, os parâmetros OD e DBO permanecem em conformidade com a Resolução CONAMA n ${ }^{\circ}$ 357/2005 (Classe 2) em toda a extensão do trecho estudado (36,8 km), enquanto o parâmetro CT passa a estar em conformidade em $58,4 \%$ do trecho. Por outro lado, para baixas vazões $\left(\mathrm{Q}_{90}=1,9 \mathrm{~m}^{3} \mathrm{~s}^{-1}\right)$, os parâmetros OD e DBO também passam a apresentar desconformidades

Tabela 3 - Coeficientes calibrados nesta pesquisa e valores de referência.

\begin{tabular}{|c|c|c|c|c|}
\hline Coeficientes & Descrição & Unidade & Faixas de valores* & Valores calibrados \\
\hline $\mathrm{K}_{\mathrm{b}}$ & Coeficiente de decaimento bacteriano & $\mathrm{d}^{-1}$ & 0,50 a 1,50 & 0,50 \\
\hline$K_{d}$ & Coeficiente de remoção de DBO & $d^{-1}$ & 0,08 a 1,00 & 0,68 \\
\hline
\end{tabular}

*Von Sperling (2007), **valor médio obtido por meio da aplicação da Equação (10), a qual foi ajustada conforme mostrado na Figura 4C. 


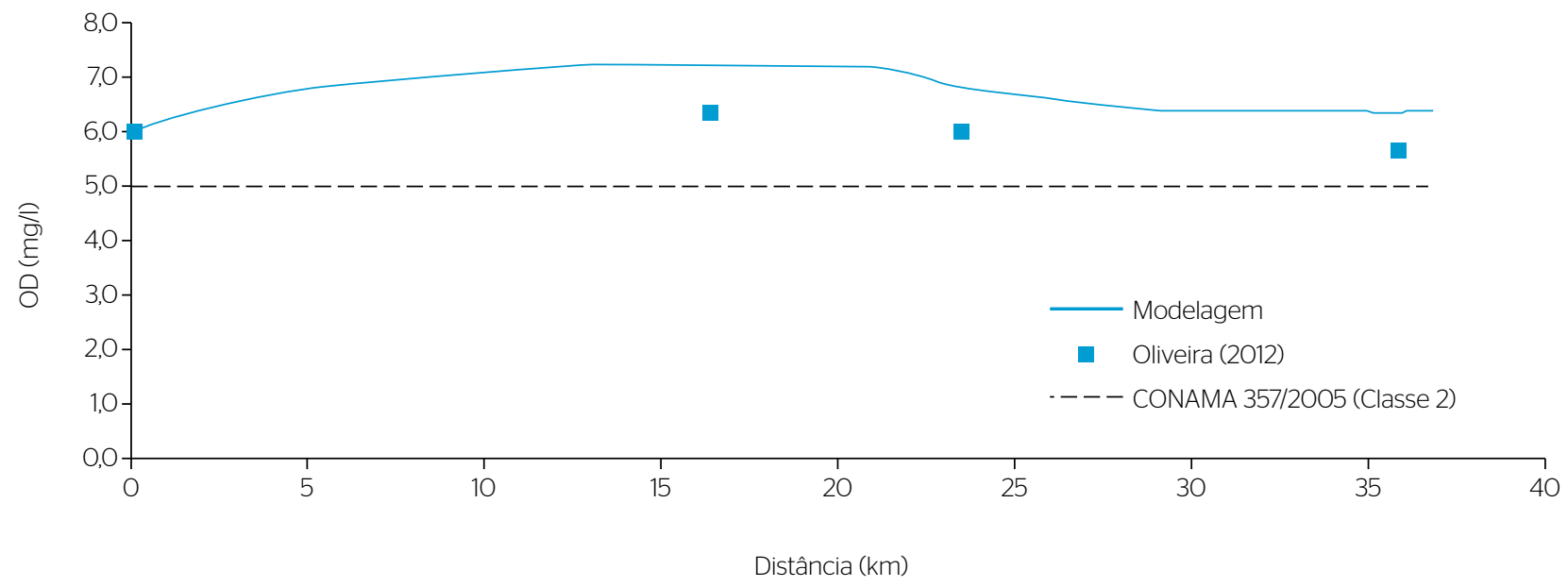

Figura 8 - Validação do modelo calibrado com dados de OD obtidos por Oliveira (2012) e comparação com o limite estabelecido na Resolução CONAMA n० 357/2005 para a Classe 2.

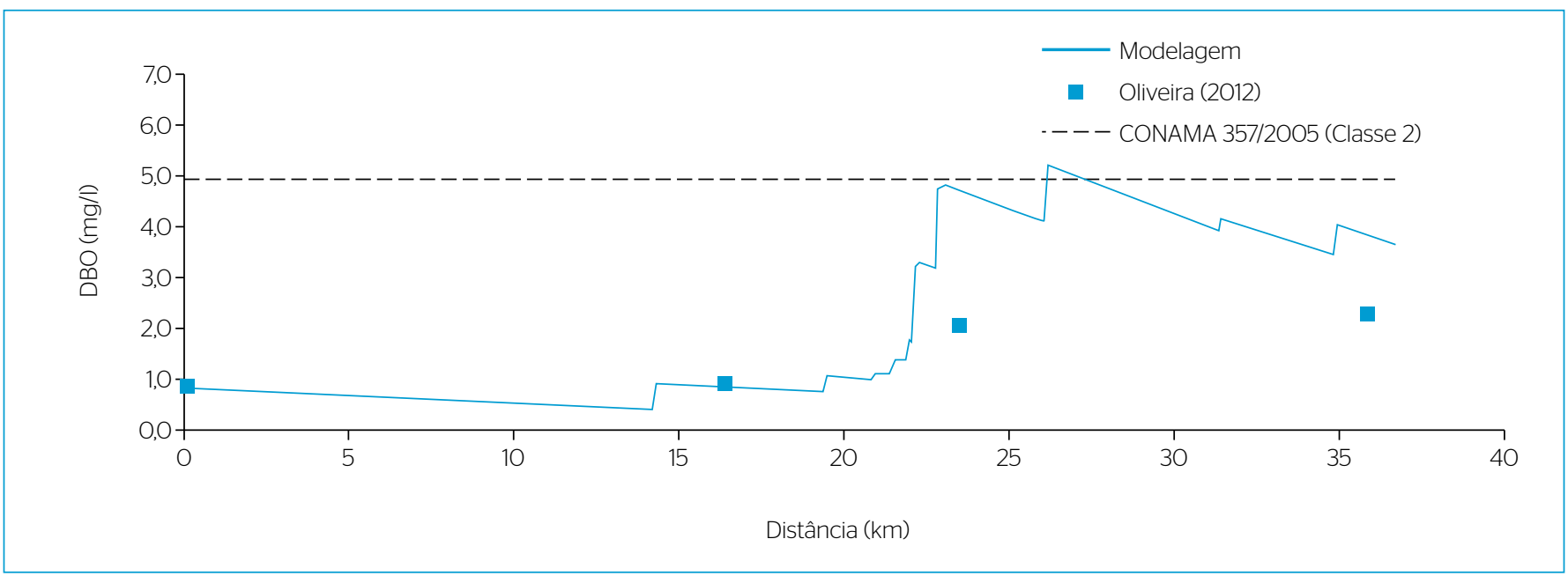

Figura 9 - Validação do modelo calibrado com dados de DBO obtidos por Oliveira (2012) e comparação com o limite estabelecido na Resolução CONAMA n० 357/2005 para a Classe 2.

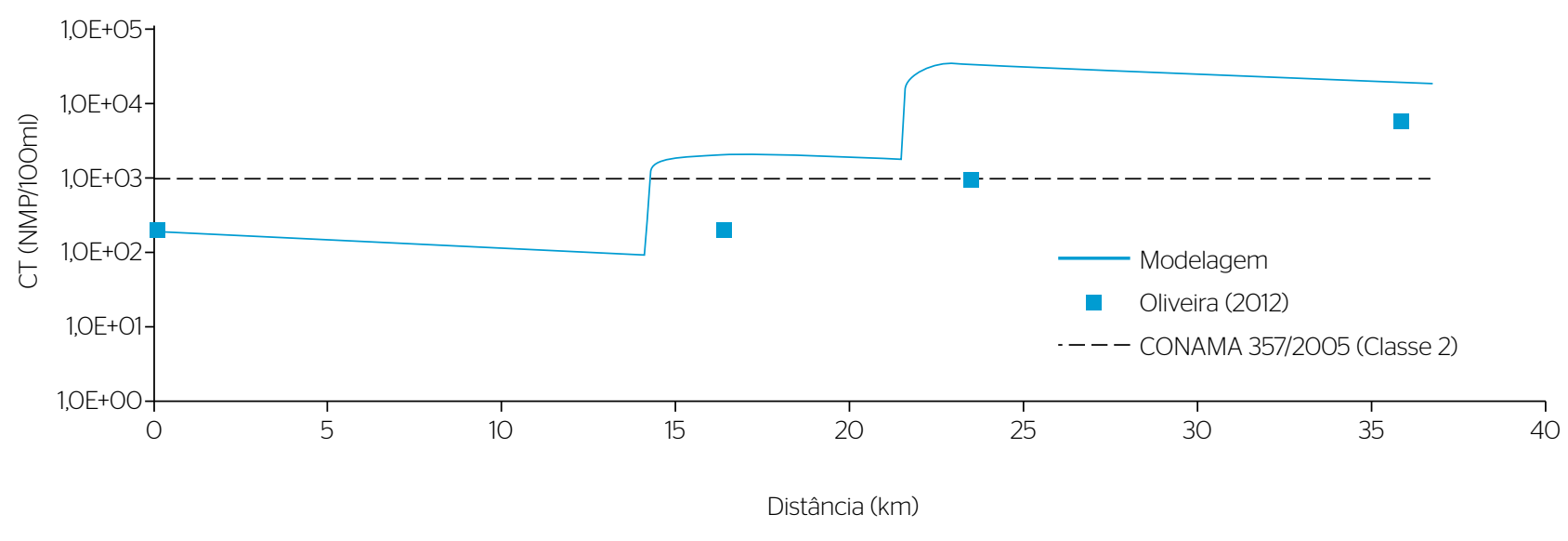

Figura 10 - Validação do modelo calibrado com dados de CT obtidos por Oliveira (2012) e comparação com o limite estabelecido na Resolução CONAMA n० 357/2005 para a Classe 2. 
com relação à Resolução CONAMA nº 357/2005 (Classe 2) no trecho estudado. Cabe salientar que as mesmas tendências gerais de aumento de OD e redução de DBO e CT com a vazão do rio foram verificadas por meio de simulações de Sabóia (2011) no rio Jaguaribe, Ceará. Ning et al. (2001) também reportam melhorias da qualidade da água em rios durante os períodos chuvosos devido ao efeito da diluição das

A

B

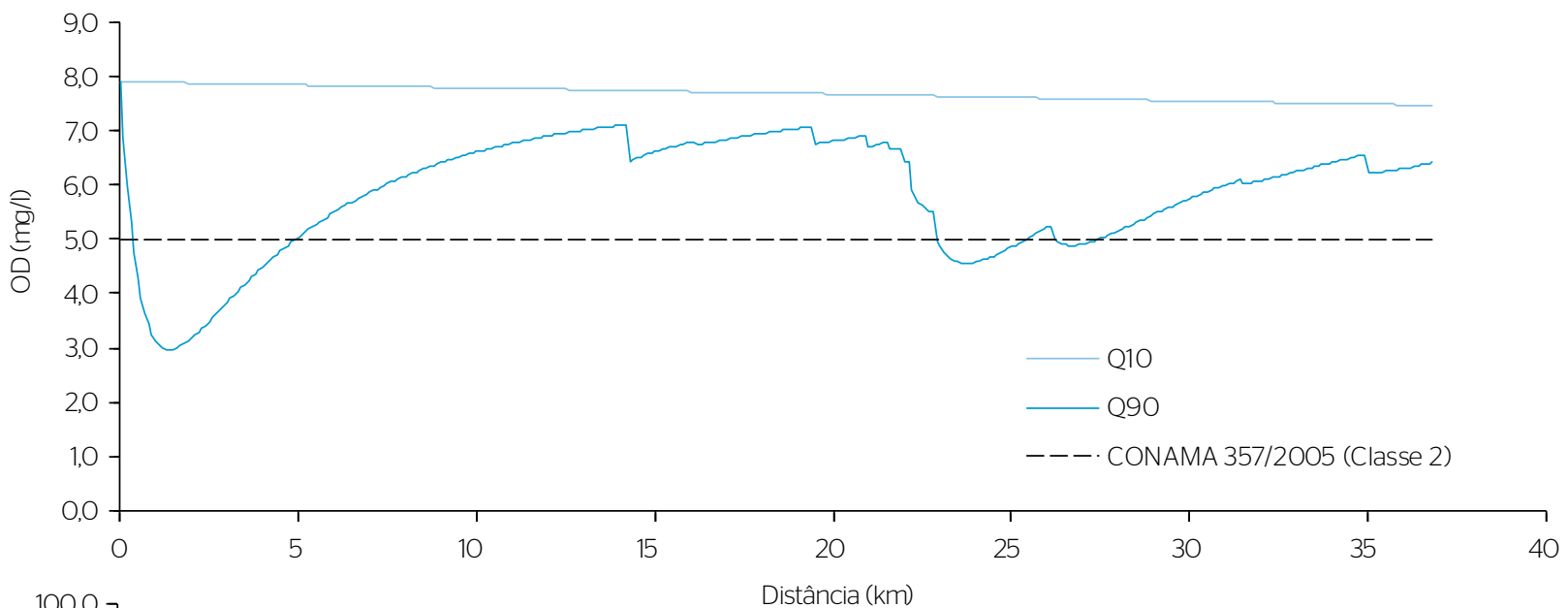

C

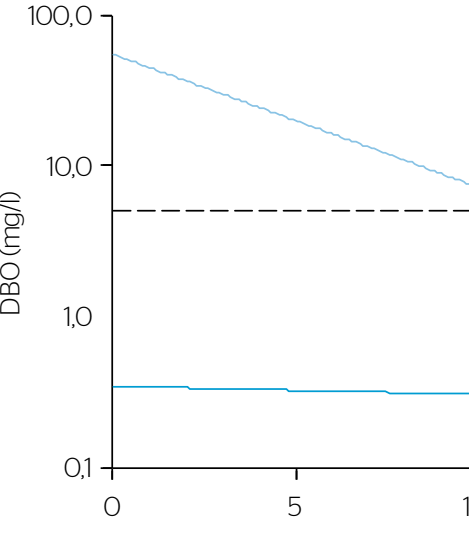

Distância $(\mathrm{km})$

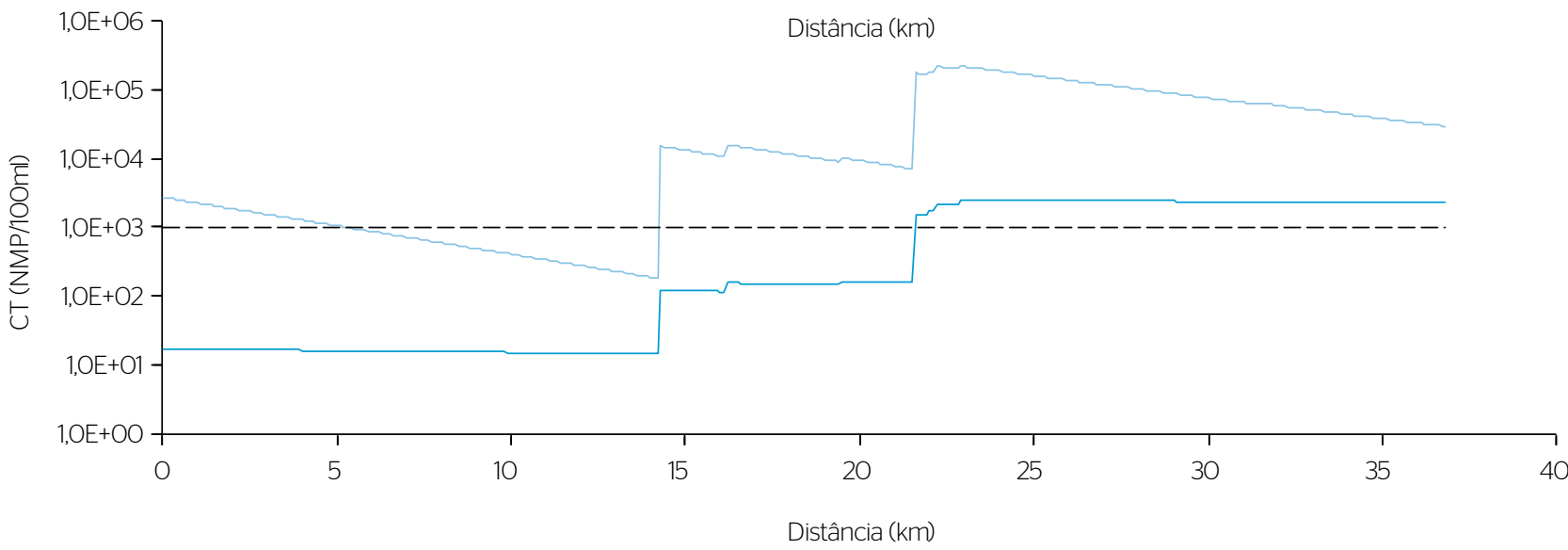

Figura 11 - Simulação de cenários para diferentes vazões $\left(Q_{90}=1,9 \mathrm{~m}^{3} \mathrm{~s}^{-1}\right.$ e $\left.\mathrm{Q}_{10}=304 \mathrm{~m}^{3} \mathrm{~s}^{-1}\right)$ e comparação com os limites estabelecidos na Resolução CONAMA n० 357/2005 para a Classe 2: (a) OD, (b) DBO e (c) CT. De acordo com os resultados da calibração do modelo, espera-se um desvio máximo entre medida e modelagem de aproximadamente $20 \%$. 
cargas. Todavia, é importante mencionar que tanto nos estudos supracitados como na presente pesquisa, não foi considerado um possível efeito de carreamento de cargas adicionais advindas do escoamento superficial. Além disso, também foram desconsiderados os possíveis impactos de ressuspensão de cargas presentes no sedimento do leito dos rios nos períodos de cheias.

\section{CONCLUSÃO}

Esta pesquisa apresentou uma aplicação inédita da plataforma QUAL-UFMG para modelagem da qualidade da água em um rio localizado na região semiárida do Brasil (município de Teresina, no Piauí) e com múltiplos lançamentos de esgoto ao longo de sua extensão. A calibração dos coeficientes do modelo referentes aos parâmetros oxigênio dissolvido, demanda bioquímica de oxigênio e coliformes termotolerantes resultou em desvios médios, entre dados medidos e modelados inferiores, a 20\%, e coeficientes de eficiência de Nash-Sutcliffe superiores a 0,75 , o que sugere que o QUAL-UFMG pode ser utilizado para tal propósito. Os resultados indicaram ainda desconformidades do parâmetro coliformes termotolerantes com relação à Resolução CONAMA n 357/2005 (Classe 2). O modelo calibrado também foi validado com dados de campo obtidos na literatura, demonstrando boa reprodutibilidade do comportamento dos três parâmetros supracitados, notadamente oxigênio dissolvido e demanda bioquímica de oxigênio. Finalmente, foram realizadas simulações do modelo para diferentes cenários de vazão do rio (mínimas e máximas) inerentes ao semiárido. Verificou-se que, mesmo para elevadas vazões, o parâmetro coliformes termotolerantes ainda apresentava desconformidade quanto à legislação vigente. Por outro lado, para baixas vazões, os três parâmetros analisados apresentaram desconformidades no trecho estudado. Isso indica que a qualidade da água em rios semiáridos é bastante vulnerável a variações de vazão entre os períodos secos e chuvosos. Esses resultados são importantes para a gestão dos recursos hídricos do estado do Piauí e demais regiões semiáridas do Brasil. É importante destacar que o modelo proposto na presente pesquisa utilizou as cargas obtidas nos estudos de campo para simulação dos cenários. No entanto, foram desconsiderados possíveis efeitos de carreamento de cargas advindas do escoamento superficial ou ressuspensão de cargas presentes no sedimento do leito dos rios que podem ocorrer durante os períodos chuvosos. Estudos estão sendo realizados para se analisar o impacto das cheias nas cargas externas e internas em rios e canais urbanos.

\section{REFERÊNCIAS}

AGÊNCIA NACIONAL DE ÁGUAS - ANA. (2014) Sistema Hidroweb. Disponível em: <http://www.snirh.gov.br/hidroweb/>. Acesso em: 15 jul. 2014.

BRASIL. (2005) CONAMA - Conselho Nacional do Meio Ambiente. Resolução n. 357. Diário Oficial da União, Brasília.

Brown, L.C. \& Barnwell, T.O. (1987) The Enhanced Stream Water Quality Models QUAL2E and QUAL2E-UNCAS (EPA/600/3-87007). Athens, GA: U.S. Environmental Protection Agency.

CÂMARA, F.M.M. (2011) Avaliação da qualidade da água no rio Poti na cidade de Teresina, Piauí. Tese (Doutorado) Universidade Estadual Paulista "Júlio de Mesquita Filho", Rio Claro

CHAPRA, S.C. (1997) Surface water-quality modeling. New York: McGraw-Hill.

Chapra, S.C.; Pelletier, G.J; Tao, H. (2008) QUAL2K: a modeling framework for simulating river and stream water quality, version 2.11: documentation and users manual. Medford, MA: Civil and Environmental Engineering Dept., Tufts University.
CHAUDHURY, R.R.; SOBRINHO, J.H.; WRIGHT, R.M.; SREENIVAS, M. (1998) Dissolved oxygen modeling of the blackstone river (Northeastern United States). Water Research, v. 32, n. 8 p. 2400-2412.

GASTALDINI, M.C.C.; SEFFRIN, G.F.F.; PAZ, M.F. (2002) Diagnóstico atual e previsão futura da qualidade das águas do Rio Ibicuí utilizando o modelo QUAL2E. Engenharia Sanitária e Ambiental, v. 7, n. 3/4, p. 129-138.

MOURÃO JÚNIOR, P.R. (2010) Aplicação do modelo de autodepuração de qualidade das águas QUAL-UFMG: estudo de caso sub-bacia do rio Piracicaba. Dissertação (Mestrado) Universidade Federal de Ouro Preto, Ouro Preto.

Nash, J.E. \& Sutcliffe, J.V. (1970) River flow forecasting through conceptual models, part I - a discussion of principles. Journal of Hydrology, v. 10, p. 282-290.

Ning, S.K.; Chang, N.B.; Yang, L.; Chen, H.W.; Hsu, H.Y. (2001) Assessing pollution prevention program by QUAL2E simulation analysis for the Kao-Ping River Basin, Taiwan. Journal of Environmental Management, v. 61, p. 61-76. 
OLIVEIRA, L.N. (2O12) Estudo da variabilidade sazonal da qualidade da água do rio Poti em Teresina e suas implicações na população local. Dissertação (Mestrado) - Universidade Federal do Piauí, Teresina.

PALMIERI, V. \& CARVALHO, R.J. (2006) QUAL2E model for the Corumbatai River. Ecological Modelling, v. 198, n. 1, p. 269-275.

PORTO, M.F.A.; KNAPIK, H.G.; FERNANDES, C.V.S.; BASSANESI, K. (2011) Qualidade da água da bacia do Rio Iguaçu: diferenças conceituais entre os modelos QUAL2E e QUAL2K. Revista Brasileira de Recursos Hidricos, v. 16, n. 2, p. 75-88.

PORTO, R.M. (2006) Hidráulica básica. 4a ed. São Carlos: Escola de Engenharia de São Carlos, Universidade de São Paulo.

Sabiá, R.J. (2008) Estudo do padrão de emissão de poluentes para o enquadramento de rios intermitentes: estudo de caso do Rio Salgado/ CE. Tese (Doutorado) - Universidade Federal do Ceará, Fortaleza.

SABÓIA, M.A.M. (2O11) Desenvolvimento de modelo de qualidade da água em rios com vistas a avaliação custo-efetividade do enquadramento dos corpos d'água. Dissertação (Mestrado) Universidade Federal do Ceará, Fortaleza.
SALLA, M.R.; PEREIRA, C.E.; ALAMY FILHO, J.E.; PAULA, L.M.; PINHEIRO, A.M. (2013) Estudo da autodepuração do Rio Jordão, localizado na bacia hidrográfica do Rio Dourados. Engenharia Sanitária e Ambiental, v. 18, n. 2, p. 105-114.

SEMAR - Secretaria Estadual de Meio Ambiente e Recursos Hídricos. (2004) Bacia do Rio Poti. Atlas de abastecimento de água do Estado do Piauí. 1 CD-ROM.

SILVA, N.G.M. (2007) Modelagem da qualidade de água no trecho de vazão reduzida (TVR) do aproveitamento hidrelétrico de Capim Branco I do Rio Araguari-MG. Dissertação (Mestrado) - Universidade Federal de Minas Gerais, Belo Horizonte.

Teodoro, A.; Ide, C.N.; Ribeiro, M.L.; Brich, S.A.O.; Silva, J.B. (2013) Implementação do conceito capacidade de diluição de efluentes no modelo de qualidade da água QUAL-UFMG: estudo de caso no Rio Taquarizinho (MS). Engenharia Sanitária e Ambiental, v. 18, n. 3, p. 275-288.

VON SPERLING, M. (2007) Estudos e modelagem da qualidade da água dos rios. Belo Horizonte: UFMG. 588p. 